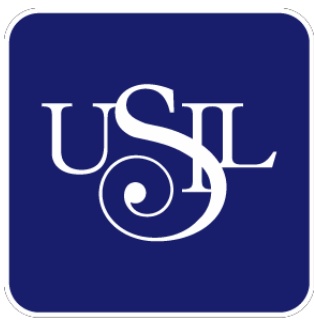

UNIVERSIDAD

SAN IGNACIO

DE LOYOLA

ESCUELA DE POSTGRADO

Maestría en Administración de Negocios - Executive MBA

\title{
PLAN DE NEGOCIO PARA DESARROLLAR LAS TELECOMUNICACIONES EN LAS LOCALIDADES RURALES DEL PERÚ
}

Trabajo de Investigación para optar el grado de Maestro en Administración de Negocios - Executive MBA

\author{
ALEJANDRINA MILAGROS CHIRINOS LEIVA \\ CESAR JESUS FRANCISCO FIGUEROA GALLARDO \\ GUSTAVO FELIX MAMANI HERRERA \\ ORLANDO ZUASNABAR TAPIA
}

\author{
Asesor: \\ José Antonio Chou Flores \\ Lima - Perú \\ 2018
}




\section{Resumen Ejecutivo}

El presente plan de negocio busca demostrar que existe la oportunidad de conectar a más peruanos que se encuentran ubicados en los distintos centros poblados más alejados del país. Gracias a la legislación vigente, existe la posibilidad de crear un nuevo modelo de negocio en el sector de las telecomunicaciones en donde un operador móvil licenciado pueda generar negocios con emprendedores que faciliten el despliegue, mantenimiento y desarrollo comercial en nuevos mercados ubicados en las zonas rurales del país llevando conectividad a través de servicios móviles con datos y con una política de innovación en el despliegue de celdas empleando socios tecnológicos como Google, Facebook entre otros.

Para evaluar el proyecto, Telefónica del Perú S.A.A. propone la creación de una sociedad que junto a potenciales socios como Google, Facebook, BID (Banco Interamericano de Desarrollo) o CAF (Banco de Desarrollo para América Latina), en donde Telefónica del Perú S.A.A. participaría como socio con una participación del 50\% y cuya empresa creada no consolidara estados financieros con la empresa matriz en Perú.

La nueva sociedad se encargará de desplegar infraestructura móvil disruptiva con nuevos modelos que permitan operar como una Low Cost Telco sin sacrificar la calidad del producto que para este caso es el Internet Móvil. Para tener información relevante que permita monetizar la oportunidad rural, Telefónica del Perú, ha desplegado celdas móviles en aproximadamente 
2,500 localidades rurales a nivel nacional utilizando tecnología tradicional (las que actualmente emplean todos los operadores móviles en Perú), estas localidades cumplen con el mismo perfil de población, características geográficas y económicas de las localidades rurales a las cuales va dirigido el proyecto.

Existen dos clasificaciones de localidades en el mundo Telco, las primeras denominadas Overlay (Localidad donde ya existe señal móvil con tecnología $2 \mathrm{G}$ - Solo voz) y localidades denominadas Greenfield (Localidad donde no existe ningún tipo de cobertura móvil), las celdas desplegadas por Telefónica del Perú, nos permiten obtener información sobre la demanda real de los usuarios rurales, tanto en uso de minutos para hablar, el consumo de datos para navegar por internet móvil y su frecuencia de recarga considerando que en su mayoría son usuarios prepagos. La denominación Overlay significa además que se puede hacer un upgrade de la tecnología pasando de tener cobertura $2 \mathrm{G}$ a $3 \mathrm{G}$, tal es así que de las 2,500 localidades 65 de ellas ya tienen tecnología 3G y con ello podemos obtener información del uso que le dan al servicio móvil el mismo que nos permitirá proyectar la demanda de los usuarios y trasladarlo a las capacidades que deben tener nuestras antes en la planificación del despliegue móvil rural.

Algunos se preguntarán, ¿Por qué si Telefónica del Perú es un operador grande, simplemente invierte más en zonas rurales sin necesidad de compartir sus ganancias con otro socio? La respuesta es simple, Telefónica del Perú es el mayor operador de telecomunicaciones del Perú brindando servicio de voz, datos, TV, interconexiones entre otros cuyo foco de operación son las zonas urbanas donde existe una alta competencia lo cual obliga a invertir en 
campañas y actualizaciones de la planta desplegada para hacerle frente a los otros operadores y con ello desprioriza la inversión en zonas rurales, a ello se le suma la complejidad de la operación de una gran empresa, en donde los procesos de compras, logísticos, mantenimiento entre otros, siguen procesos estandarizados que hace que demore más su ejecución.

Es por ello por lo que apuesta por un modelo de empresa ajena a la estructura matriz de Telefónica del Perú para que pueda operar como un startup low cost con procesos ágiles, empleando diversas tecnologías no tradicionales que permitan llevar comunicación a bajo costo y con un socio que busque desarrollar las zonas rurales del país con la finalidad de llevar las telecomunicaciones todos.

Con el éxito del presente proyecto, Telefónica del Perú pretende desarrollar el mismo modelo en las operaciones de los otros países de la región que presentan las mismas características geografías en donde empresas de telecomunicaciones tradicionales no pueden llegar por el alto costo operativo. 
Tabla de Contenidos

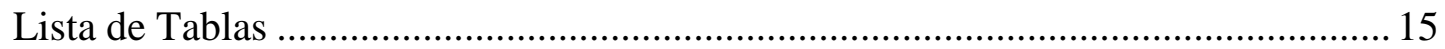

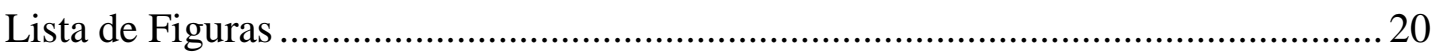

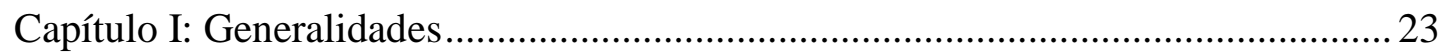

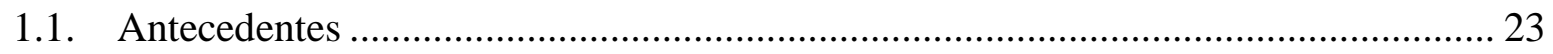

1.2. Determinación del problema u oportunidad.................................................. 25

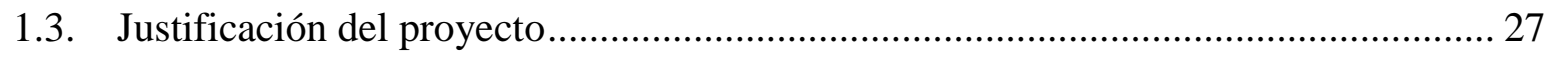

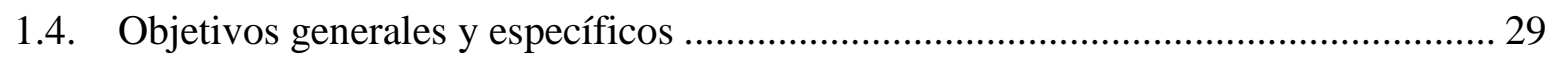

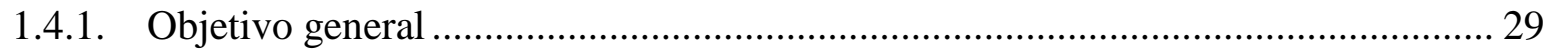

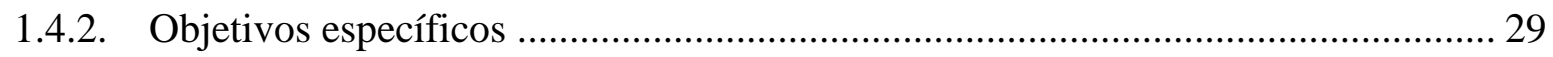

1.5. Alcances y limitaciones de la investigación..................................................... 29

Capítulo II: Estructura económica del sector .................................................... 31

2.1. Descripción del estado actual de la industria ................................................ 33

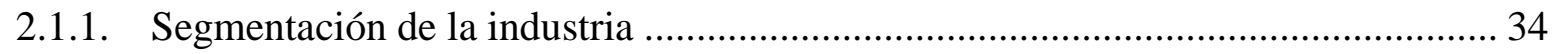

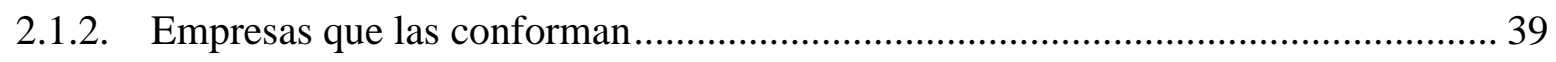

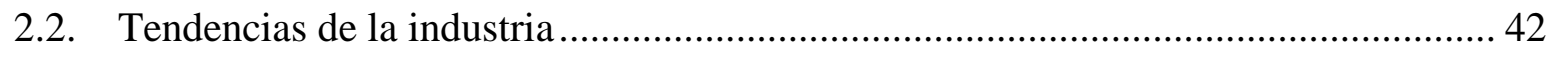

2.3. Análisis estructural del sector industrial ..................................................... 44

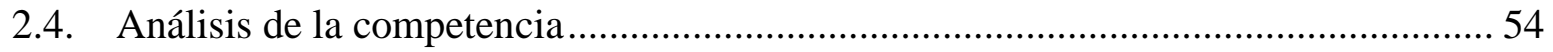


2.4.1. Empresas que ofrecen el mismo producto o servicio 54

2.4.2. Participación del mercado ........................................................................ 55

2.4.3. Matriz de perfil competitivo...................................................................... 57

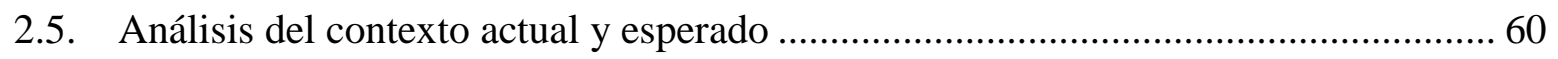

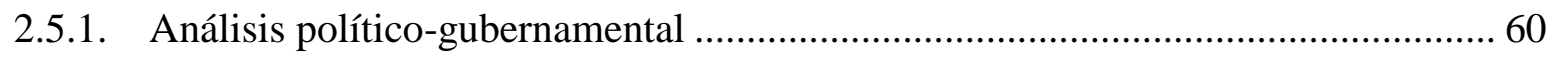

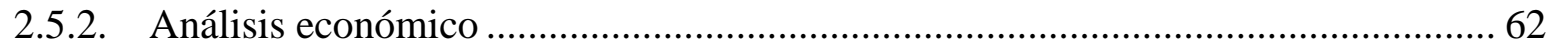

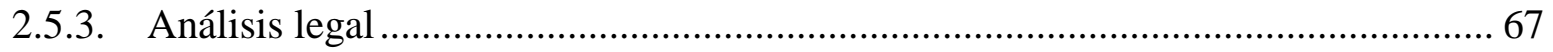

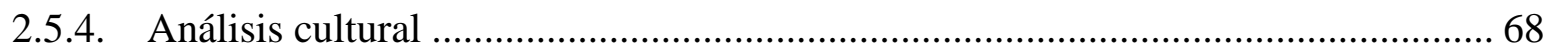

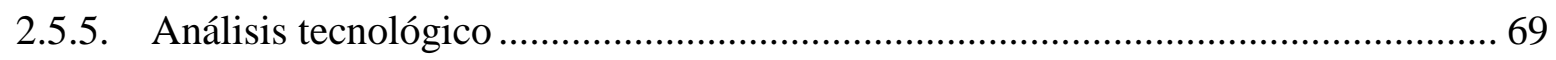

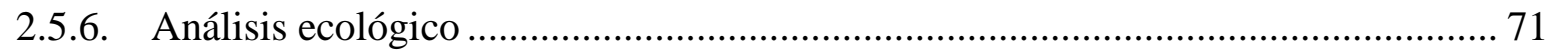

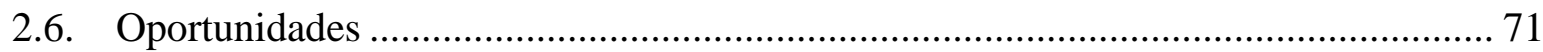

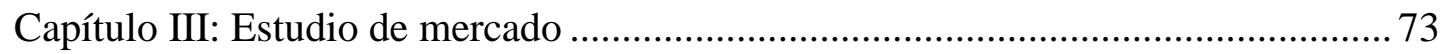

3.1. Descripción del servicio o producto.............................................................. 73

3.2. Selección del segmento del mercado ........................................................... 74

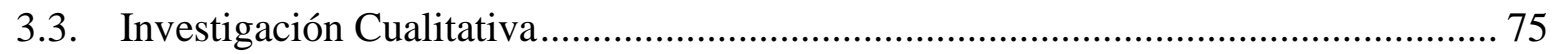

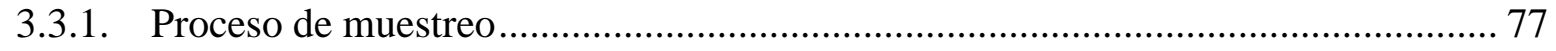

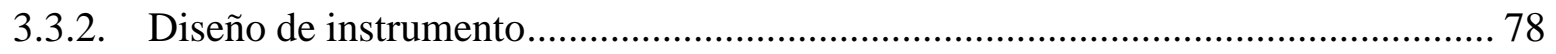

3.3.3. Análisis y procesamiento de datos ............................................................. 81

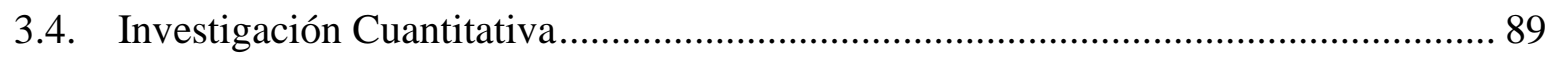


3.4.3. Proceso de muestreo de la investigación...................................................... 90

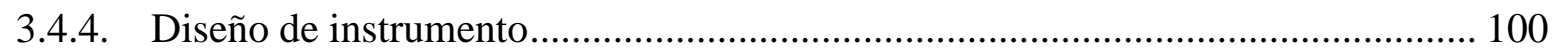

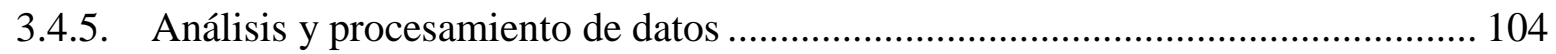

3.5. Conclusiones y recomendaciones del estudio de mercado cualitativo y cuantitativo 120

3.5.1. Conclusiones estudio cuantitativo................................................................ 120

3.5.2. Recomendaciones estudio cuantitativo .................................................. 121

3.6. Perfil del consumidor tipo y sus variantes .................................................. 122

Capítulo IV: Proyección del mercado objetivo .................................................. 126

4.1. El ámbito de la proyección .......................................................................... 126

4.2. Selección del método de proyección ................................................................. 126

4.2.1. Mercado Potencial ...................................................................................... 127

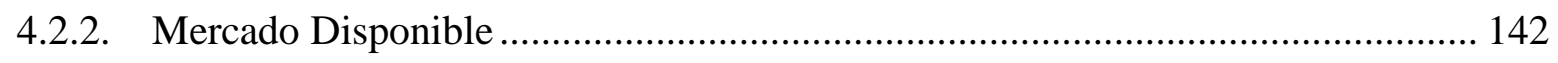

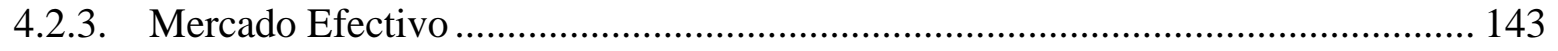

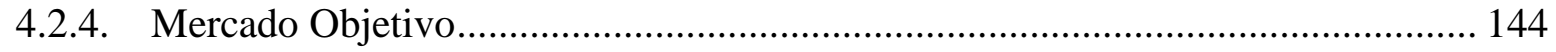

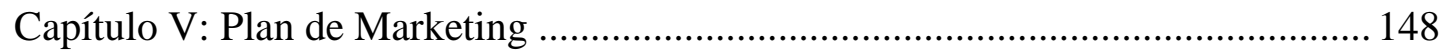

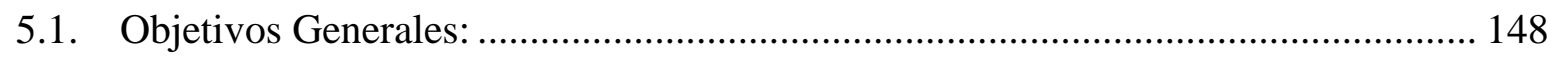

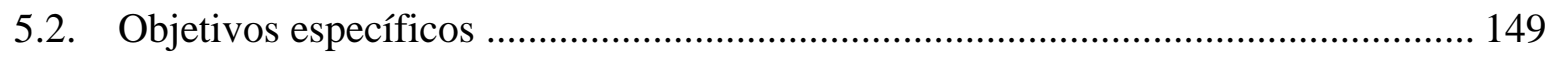

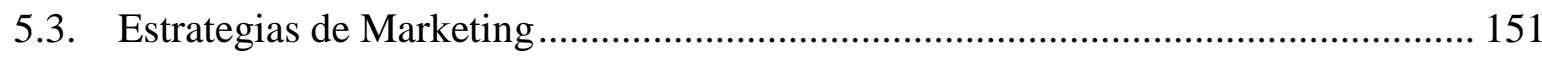




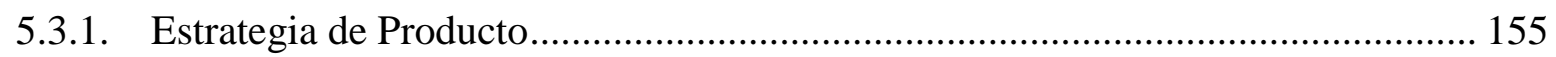

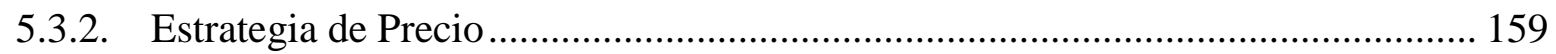

5.3.3. Estrategia de Plaza y Distribución ....................................................................... 165

5.3.4. Estrategia de Promoción y Publicidad .................................................................... 166

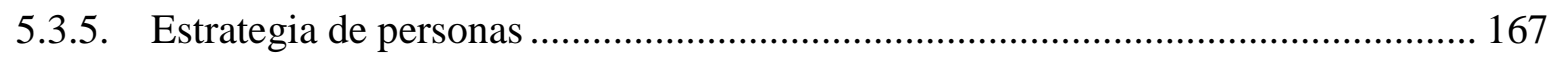

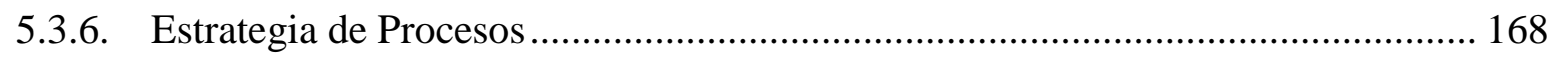

5.3.7. Estrategia de presencia física ....................................................................... 168

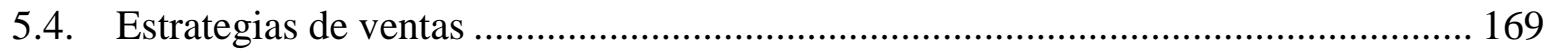

Capítulo VI: Pronóstico de Ventas.......................................................................... 170

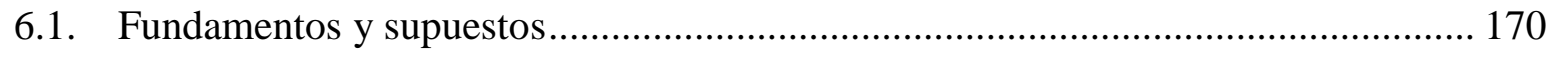

6.2. Justificación..................................................................................................... 179

6.3. Análisis de los riesgos y aspectos críticos que impactan en el pronóstico................ 180

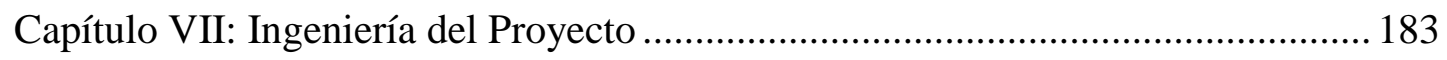

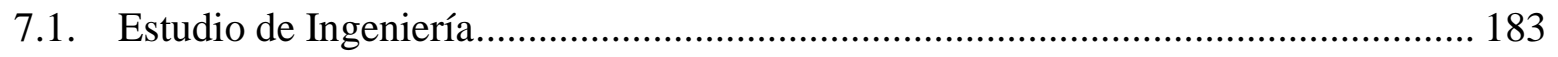

7.1.1. Modelamiento y selección de procesos productivos ............................................. 183

7.1.2. Selección de equipamiento............................................................................. 189

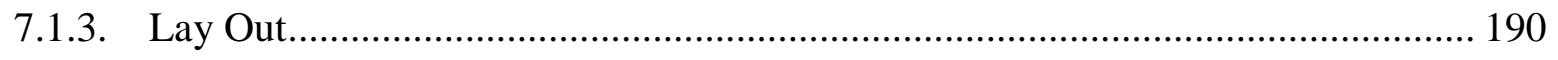

7.1.4. Distribución de equipos y maquinarias ................................................................ 193

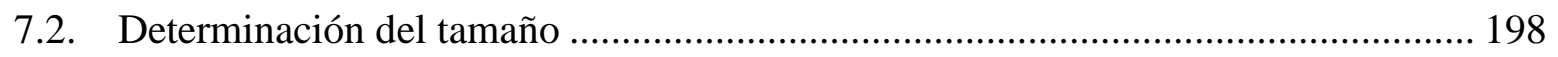




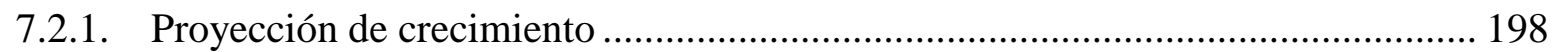

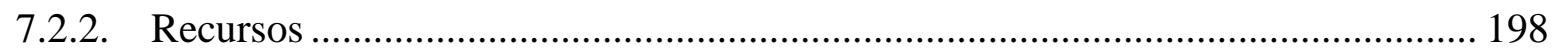

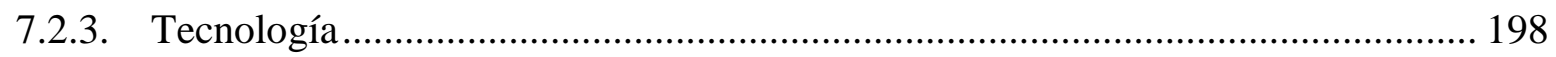

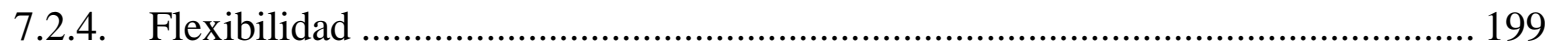

7.2.5. Selección del tamaño ideal............................................................................... 199

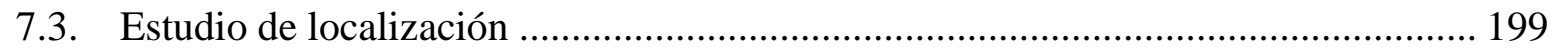

7.3.1. Definición de factores de ubicación ...................................................................... 199

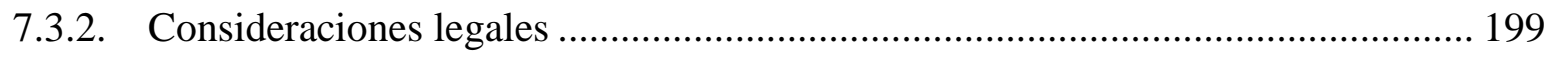

7.4. Determinación de la localización óptima ................................................................... 200

Capítulo VIII: Aspectos Organizacionales............................................................... 201

8.1. Caracterización de la cultura organizacional deseada ................................................ 201

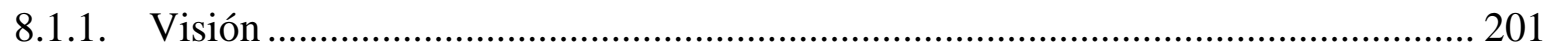

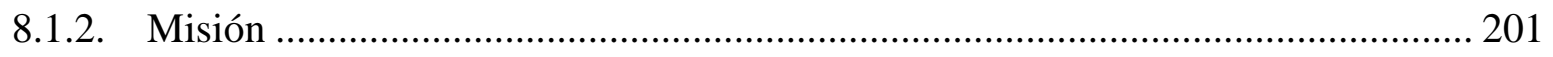

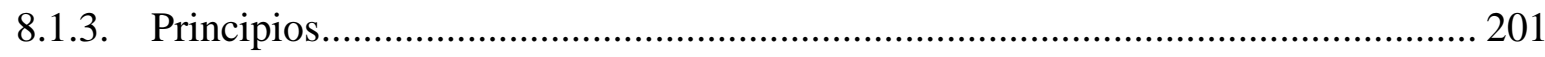

8.2. Formulación de estrategias del negocio ................................................................ 202

8.3. Determinación de las ventajas competitivas críticas ................................................ 202

8.4. Diseño de la estructura organizacional deseada ....................................................... 202

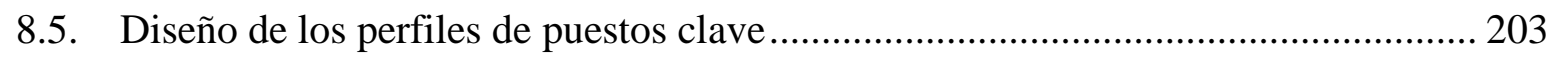

8.6. Remuneraciones, compensaciones e incentivos ....................................................... 203 
8.7. Política de recursos humanos 205

Capítulo IX: Planificación financiera. .206

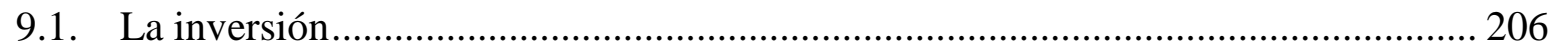

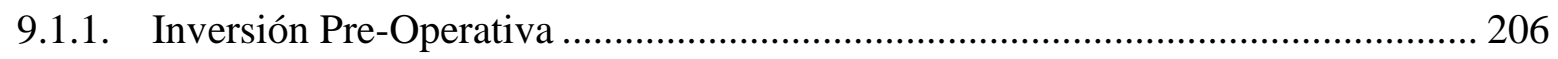

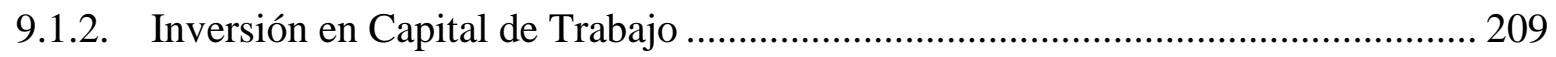

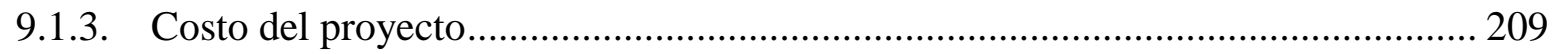

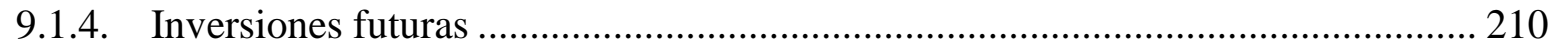

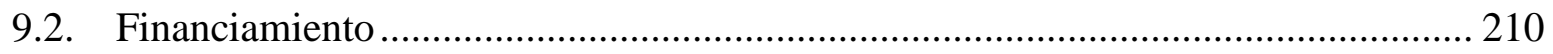

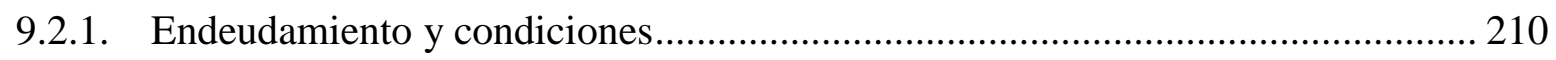

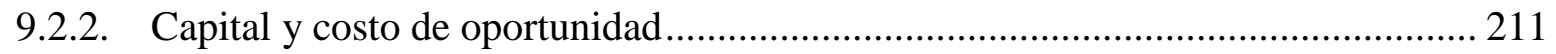

9.2.3. Costo de capital promedio ponderado ................................................................ 212

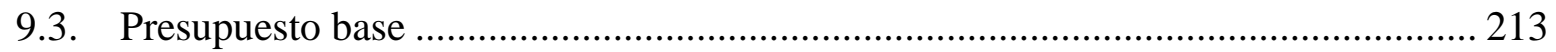

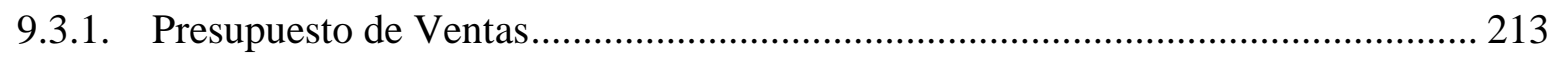

9.3.2. Presupuesto de costos de producción .................................................................... 214

9.3.3. Presupuestos de compras ............................................................................... 214

9.3.4. Presupuesto de costo de ventas ........................................................................ 215

9.3.5. Presupuesto de gastos administrativos ................................................................. 216

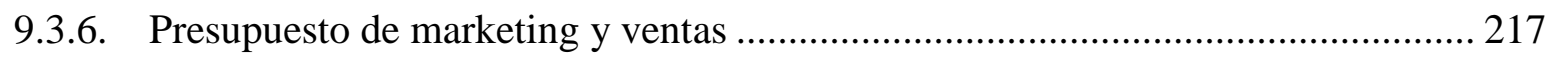

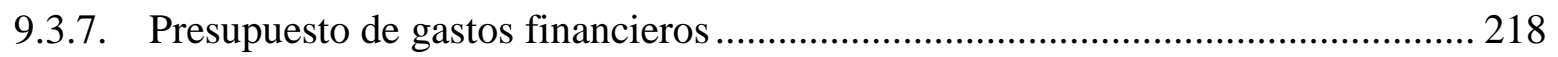




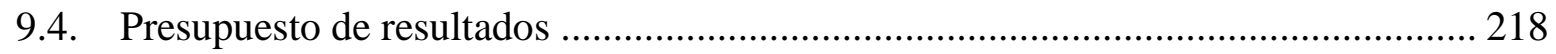

9.4.1. Estado de ganancias y pérdidas proyectado ................................................... 218

9.4.2. Estado de situación proyectado .................................................................. 219

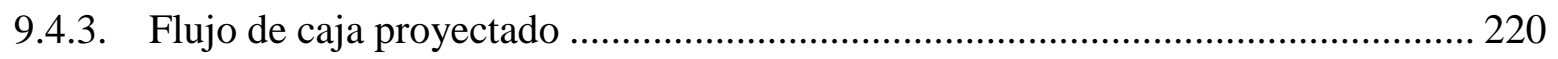

Capítulo X: Evaluación económica financiera..................................................221

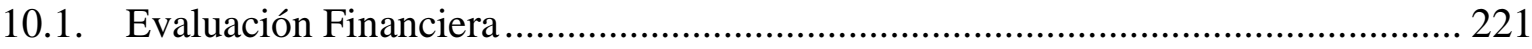

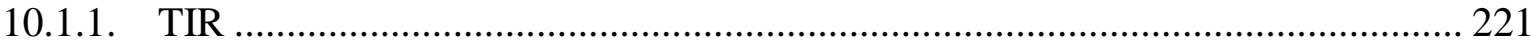

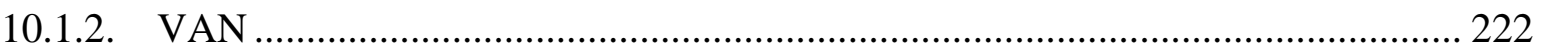

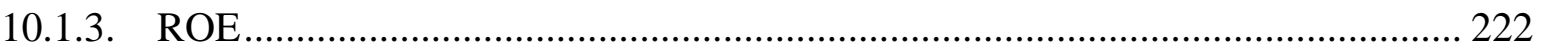

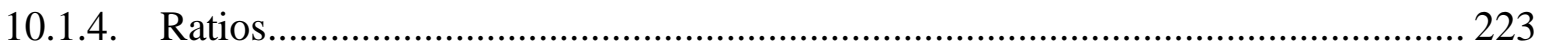

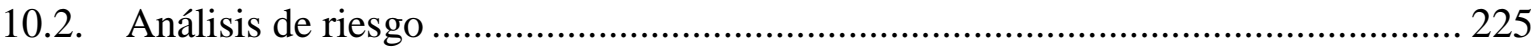

10.2.1. Análisis de punto de equilibrio .............................................................. 225

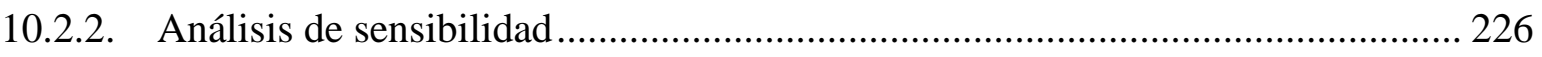

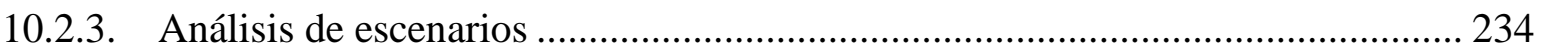

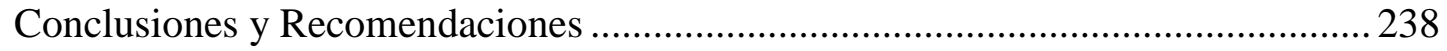

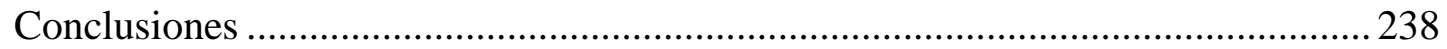

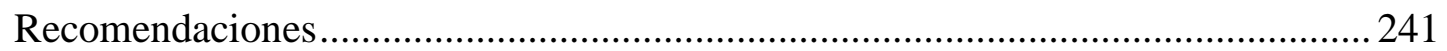

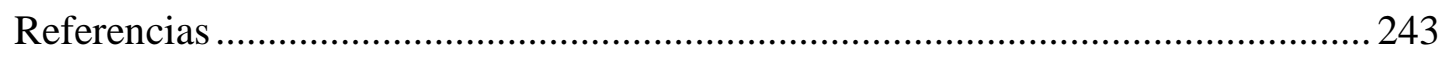

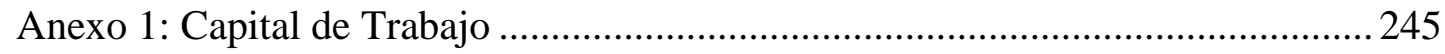


Anexo 2: Entrevistas a profundidad con expertos 248

Entrevista a profundidad $\mathrm{N}^{\circ} 01$ - Entrevista a especialista del sector, especializado en mercado de telecomunicaciones.

Anexo 3: Cuestionario para entrevistas cara a cara. .264

Anexo 4: Entrevistas cara a cara 265

Entrevista cara a cara $\mathrm{N}^{\circ} 1$ - Residente de zona Green Field 266

Entrevista cara a cara $\mathrm{N}^{\circ} 2$ - Residente de zona Green Field 268

Entrevista cara a cara $\mathrm{N}^{\circ} 3$ - Residente de zona Green Field 270

Entrevista cara a cara $\mathrm{N}^{\circ} 4$ - Residente de zona Green Field 272

Entrevista cara a cara $\mathrm{N}^{\circ} 5$ - Residente de Zona Green Field 274

Entrevista cara a cara $\mathrm{N}^{\circ} 6$ - Residente Zona Green Field 276

Entrevista cara a cara $\mathrm{N}^{\circ} 7$ - Residente Zona Green Field 278

Entrevista cara a cara $\mathrm{N}^{\circ} 8$ - Residente Zona Green Field 280

Entrevista cara a cara $\mathrm{N}^{\circ} 9$ - Residente Zona Green Field 282

Entrevista cara a cara $\mathrm{N}^{\circ} 10$ - Residente Zona Green Field 284

Entrevista cara a cara $N^{\circ} 11$ - Residente Zona Green Field 286

Entrevista cara a cara $\mathrm{N}^{\circ} 12$ - Residente Zona Green Field 288

Entrevista cara a cara $N^{\circ} 13$ - Residente Zona Green Field 290

Entrevista cara a cara $\mathrm{N}^{\circ} 14$ - Residente Zona Green Field 292 
Entrevista cara a cara $N^{\circ} 15$ - Residente Zona Green Field .......................................... 294

Entrevista cara a cara $\mathrm{N}^{\circ} 16$ - Residente Zona Green Field ......................................... 296

Entrevista cara a cara $\mathrm{N}^{\circ} 17$ - Residente Zona Green Field ........................................ 298

Entrevista cara a cara $\mathrm{N}^{\circ} 18$ - Residente Zona Green Field .......................................... 300

Entrevista cara a cara $\mathrm{N}^{\circ} 19$ - Residente Zona Green Field ........................................ 302

Entrevista cara a cara $N^{\circ} 20$ - Residente Zona Green Field .......................................... 304

Anexo 5: Cuestionario de Entrevista en Profundidad ........................................... 306

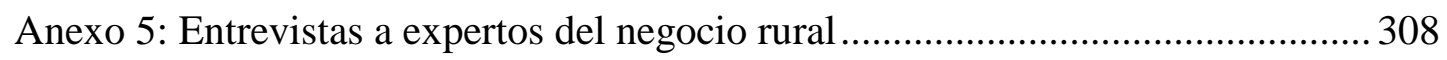

Anexo 6: Relación de Operadores de Infraestructura Móvil Rural........................... 315 
Lista de Tablas

Tabla 1 Evolución del índice mensual de la producción nacional, Año base, 2007 32

Tabla 2 Población total por área urbana y rural 34

Tabla 3 Gasto real promedio per cápita mensual, según área de residencia, región natural y dominios geográficos. 2007-2016 (Soles constantes base=2016 a precios de Lima Metropolitana) 35

Tabla 4 Hogares con acceso a las Tecnologías de Información y Comunicaciones (TIC) (Porcentaje respecto al total de hogares de cada condición de pobreza) ................................... 38

Tabla 5 Poder de negociación de los clientes............................................................... 47

Tabla 6 Poder de negociación de los proveedores ....................................................... 49

Tabla 7 Amenaza de ingreso de nuevos competidores ............................................... 51

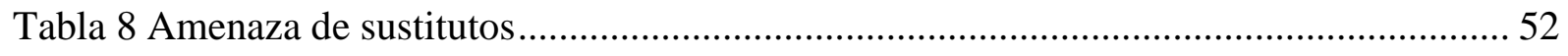

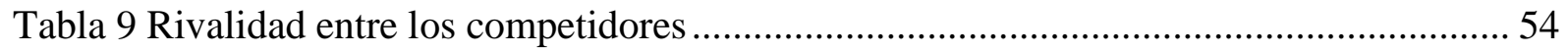

Tabla 10 Matriz de Perfil competitivo - Zona Rural ..................................................... 57

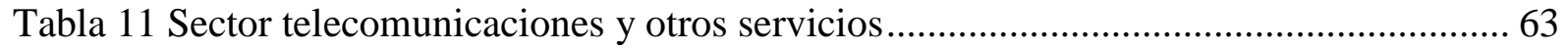

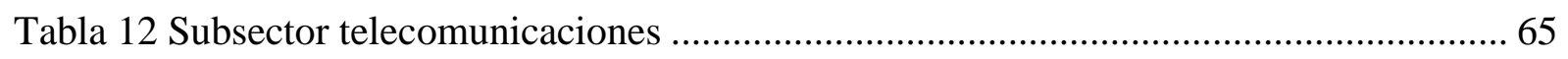

Tabla 13 Detalle del uso de los resultados de la Investigación Cualitativa ........................... 89

Tabla 14 Distribución de la población rural por departamentos ......................................... 93

Tabla 15 Población de las zonas rurales de acuerdo a los datos censales 1993, 2007 y 2017.94

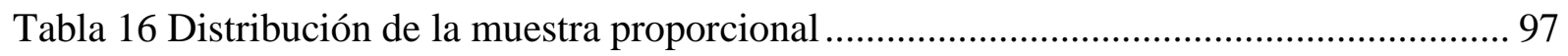

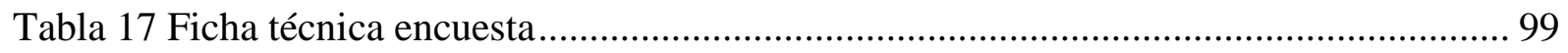




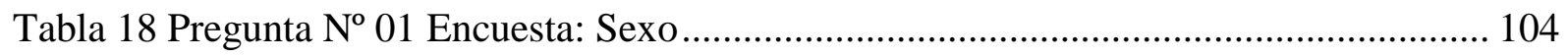

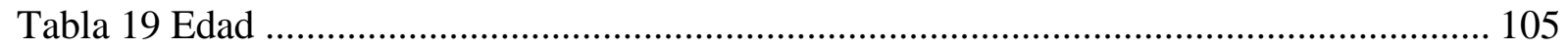

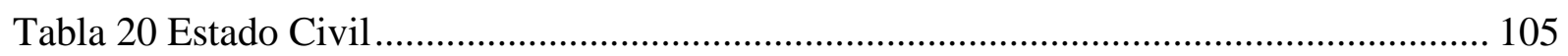

Tabla 21 Nombre del operador móvil ........................................................................ 107

Tabla 22 Tiempo de permanencia ................................................................................... 108

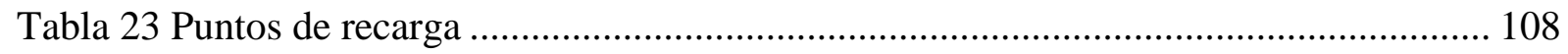

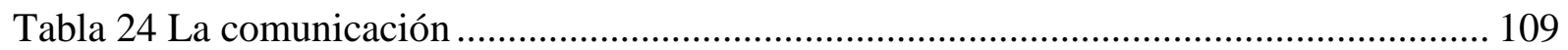

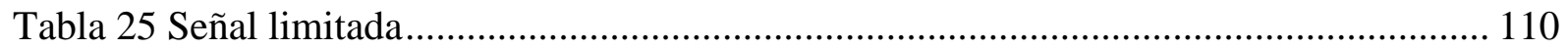

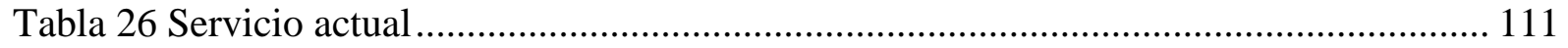

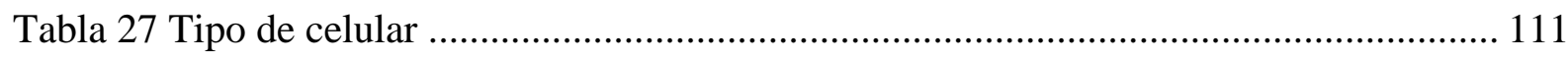

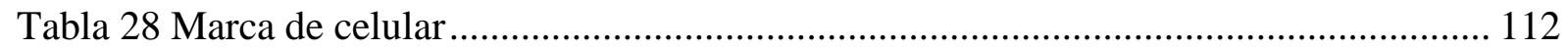

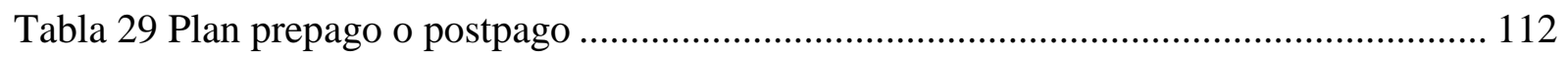

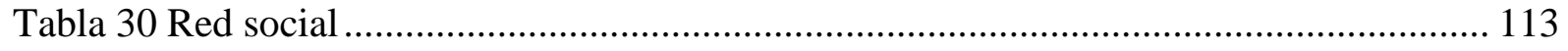

Tabla 31 Preferencia de promociones: redes sociales .......................................................... 114

Tabla 32 Preferencias: precio de equipo celular .............................................................. 115

Tabla 33 Necesidad de comunicación .................................................................................... 115

Tabla 34 Población de Amazonas proyectada (En número de personas) ………………....... 128

Tabla 35 Población de Ancash proyectada (En número de personas) ................................... 129

Tabla 36 Población de Cajamarca proyectada (En número de personas) ……….................... 130

Tabla 37 Población de Cusco proyectada (En número de personas) ………………….......... 131

Tabla 38 Población de Huánuco proyectada (En número de personas) ................................... 132

Tabla 39 Población de Junín proyectada (En número de personas)........................................ 133 
Tabla 40 Población de La Libertad proyectada (En número de personas)........................... 134

Tabla 41 Población de Lambayeque proyectada (En número de personas)......................... 135

Tabla 42 Población de Lima proyectada (En número de personas) …................................ 136

Tabla 43 Población de Loreto proyectada (En número de personas)................................... 137

Tabla 44 Población de Piura proyectada (En número de personas) .................................... 138

Tabla 45 Población de San Martin proyectada (En número de personas) ............................ 139

Tabla 46 Población de Ucayali proyectada (En número de personas) ................................ 140

Tabla 47 Mercado potencial proyectado .............................................................. 141

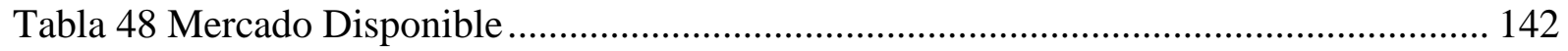

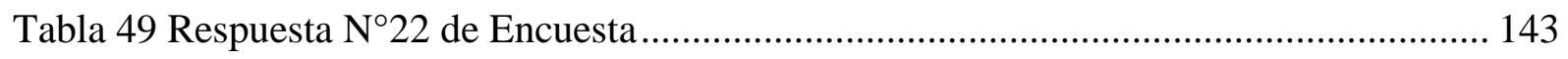

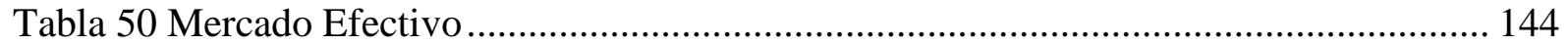

Tabla 51 Variación anual PBI - Telecomunicaciones ...................................................... 145

Tabla 52 Participación del mercado Proyectada ........................................................... 146

Tabla 53 Mercado Objetivo ...................................................................................... 147

Tabla 54 Terminología para identificar las métricas del proyecto.................................... 158

Tabla 55 Ingresos por Site Setiembre, Octubre, Noviembre y Diciembre 2017................. 161

Tabla 56 Ratio incremental poblacional .................................................................... 162

Tabla 57 Cálculo de monto promedio de recarga por semana: ....................................... 163

Tabla 58 Distribución de venta de equipos ............................................................... 165

Tabla 59 Participación del mercado ......................................................................... 170

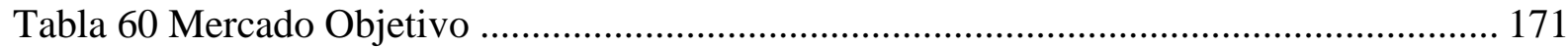

Tabla 61 Mercado Objetivo-Corregido Factor de Corrección 1.16 .................................... 172 
Tabla 62 Preferencia de montos de recarga .................................................................... 173

Tabla 63 Preferencia de frecuencia de recarga .......................................................... 173

Tabla 64 Presupuesto de Ventas Proyectado de Recargas ............................................... 174

Tabla 65 Ingresos por Comisión de Recargas ............................................................... 175

Tabla 66 Ingresos por ARPU Prepago y Postpago - Operador Móvil ............................... 176

Tabla 67 Ingresos por ARPU Prepago y Postpago-Comisión ............................................ 177

Tabla 68 Comisión por Ventas de Equipos Celulares..................................................... 178

Tabla 69 Total Ingresos por Ventas de Equipos S/................................................... 178

Tabla 70 Ingresos por Comisión de Ventas de Chips para equipos celulares...................... 179

Tabla 71 Total Ingresos por todos los conceptos OIMR S/........................................ 179

Tabla 72 Precios Small Cell 4G Parallel Wireless ............................................................ 196

Tabla 73 Precios Macro Cell 4G Parallel Wireless.......................................................... 197

Tabla 74 Planilla de Remuneraciones ........................................................................ 204

Tabla 75 Inversión Activo Fijo Instalación Small Cell 4G.............................................. 207

Tabla 76 Inversión Activo Fijo Instalación Macro Cell 4G............................................. 208

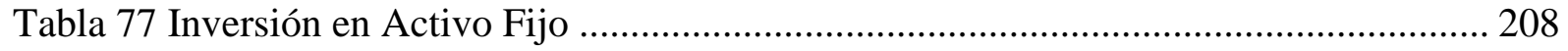

Tabla 78 Inversión Pre Operativa Estructura de Inversión Pre-Operativa ......................... 210

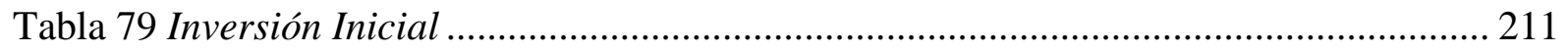

Tabla 80 Cálculo de la recuperación de inversión descontado ........................................ 212

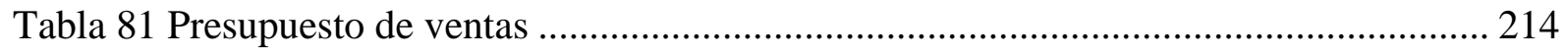

Tabla 82 Costo de Ventas ........................................................................................... 216

Tabla 83 Gastos de Administración, soles ................................................................. 217 
Tabla 84 Gastos de Ventas y Marketing, Soles................................................................ 217

Tabla 85 Estado de ganancias y pérdidas proyectado, soles ........................................... 218

Tabla 86 Estado de situación proyectado ...................................................................... 219

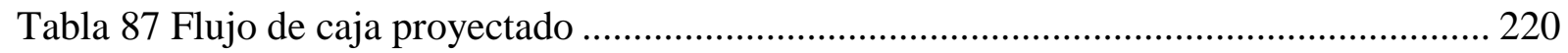

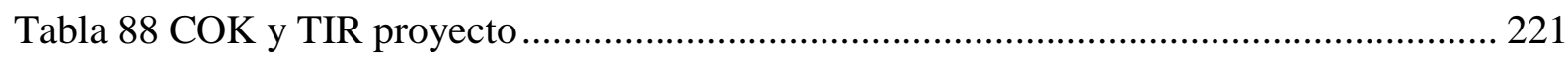

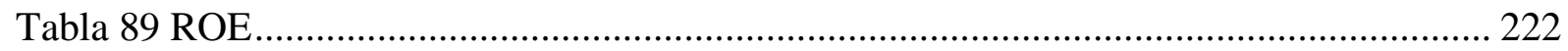

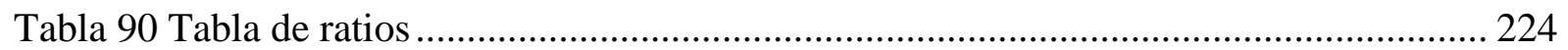

Tabla 91 Punto de equilibrio del proyecto .................................................................... 225

Tabla 92 Análisis de Sensibilidad Variación de la demanda ............................................. 227

Tabla 93 Análisis de sensibilidad, Variación del precio de repuestos ............................... 228

Tabla 94 Análisis de sensibilidad, Variación del precio segmento satelital ........................ 229

Tabla 95 Análisis de sensibilidad, variación del costo del mantenimiento.......................... 230

Tabla 96 Análisis Bidimensional Demanda - Costo Repuestos ...................................... 231

Tabla 97 Análisis Bidimensional Demanda - Costo Segmento Satelital ............................ 232

Tabla 98 Análisis Bidimensional Demanda - Costo Mantenimiento ................................. 233

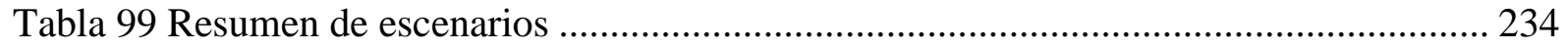

Tabla 100 Escenario con menor demanda..................................................................... 235

Tabla 101 Escenario con menor demanda y alto costo satelital...................................... 236 


\section{Lista de Figuras}

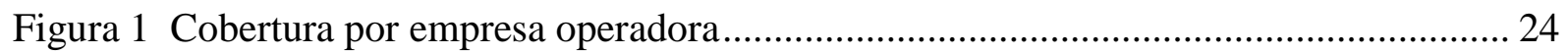

Figura 2 Hogares con algún miembro con celular ........................................................... 27

Figura 3 Evolución del ingreso real promedio per cápita mensual .......................................... 37

Figura 4 La telefonía móvil en el Perú …………………............................................... 40

Figura 5 Evolución de las líneas móviles en el Perú................................................................ 41

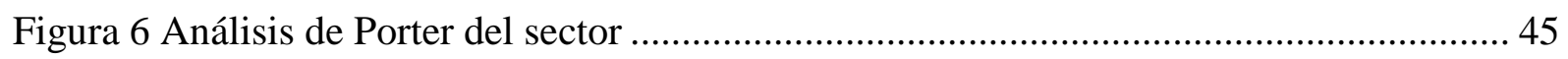

Figura 7 Participación de mercado de telefonía en el Perú ...................................................... 56

Figura 8 Crecimiento de los servicios públicos de telecomunicaciones .................................. 66

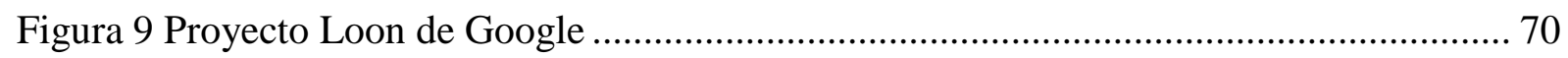

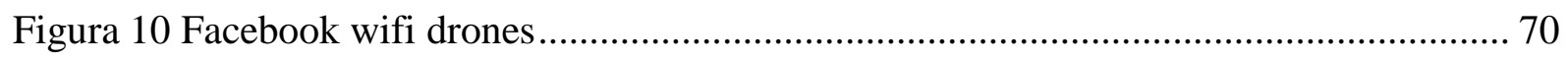

Figura 11 Distribución de personas según NSE-2017 ……………………………............ 75

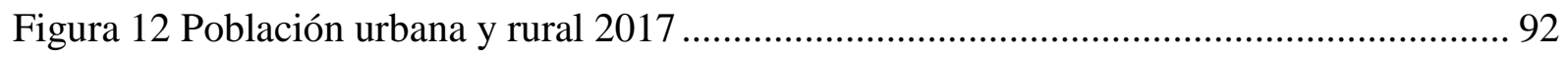

Figura 13 Encuesta de la investigación cuantitativa ......................................................... 101

Figura 14 Teléfono celular activo ................................................................................. 106

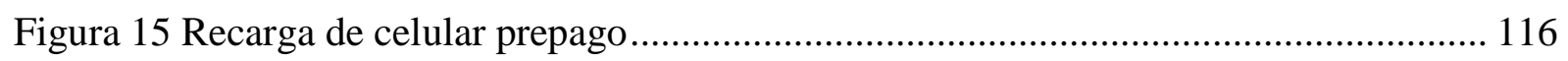

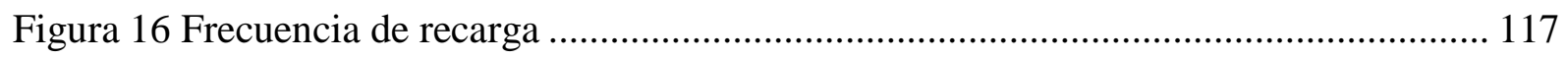

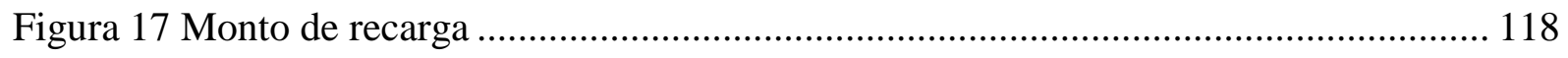

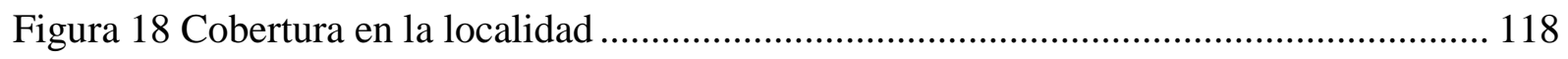

Figura 19 Opción de cambiar de operador ...................................................................... 119

Figura 20 Percepción de marca ...................................................................................... 120 


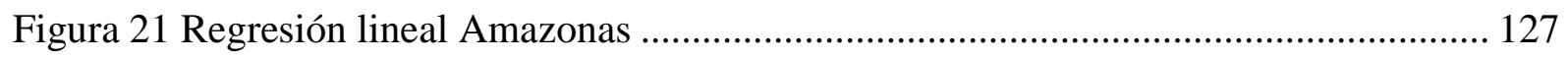

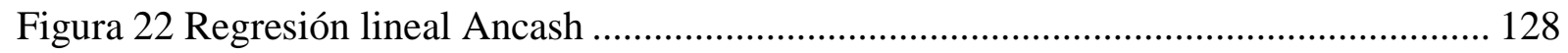

Figura 23 Regresión lineal Cajamarca ....................................................................... 129

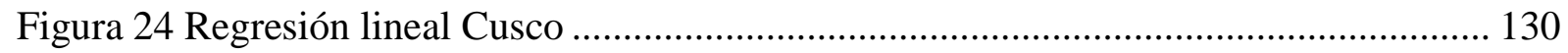

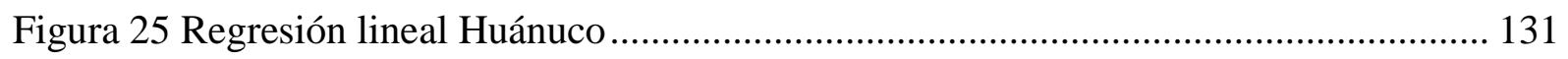

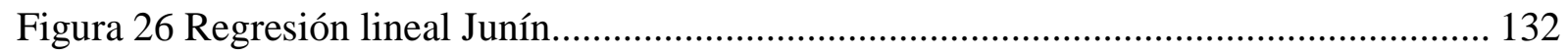

Figura 27 Regresión lineal La Libertad ..................................................................... 133

Figura 28 Regresión lineal Lambayeque..................................................................... 134

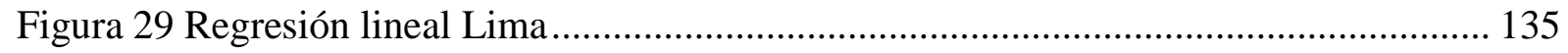

Figura 30 Regresión lineal Loreto.......................................................................... 136

Figura 31 Regresión lineal Piura.............................................................................. 137

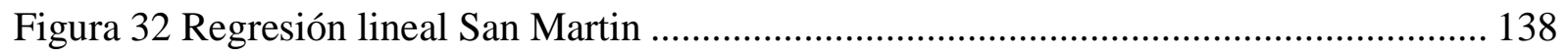

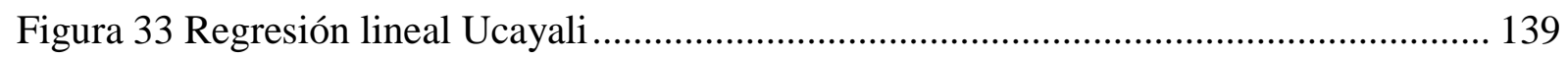

Figura 34 Estructura de la Investigación.................................................................... 154

Figura 35 Plaza y Distribución Movistar - 2018 ........................................................ 166

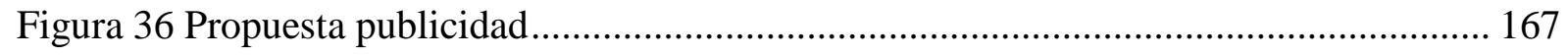

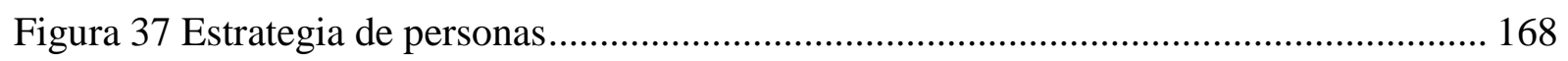

Figura 38 Diseño de red disruptivo .................................................................... 184

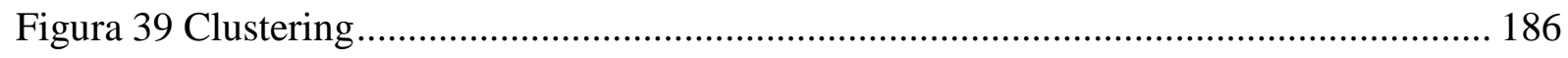

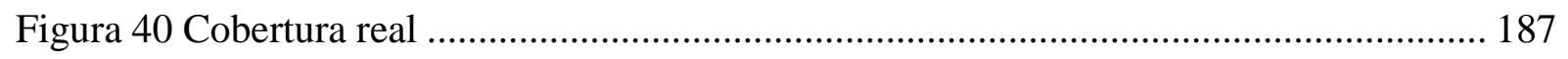

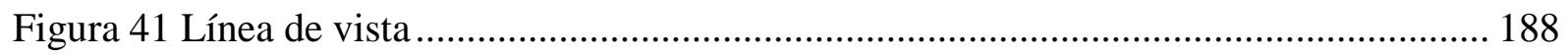

Figura 42 Distribución de la oficina principal ........................................................... 191 


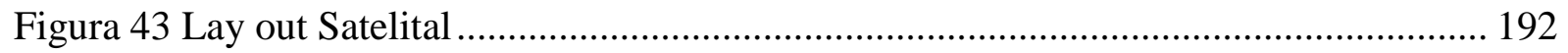

Figura 44 Lay out Radio Frecuencia ....................................................................... 192

Figura 45 Lay out Fibra Óptica ............................................................................. 193

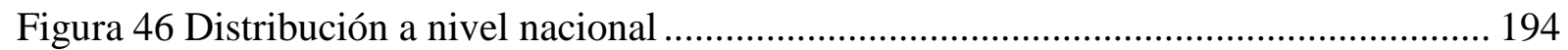

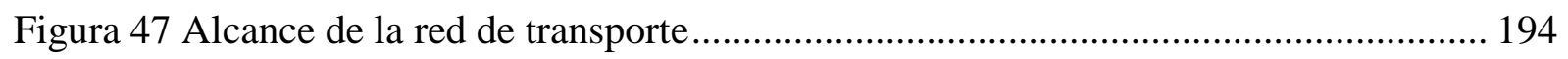

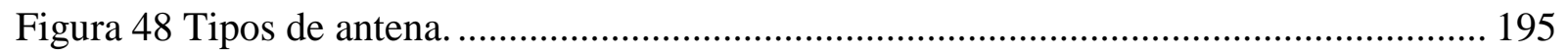

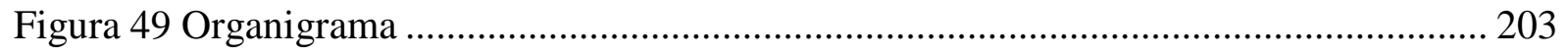

Figura 50 Diagrama de conexión de una OIMR ........................................................... 240 